\section{Review: physical diagnostic tests have low diagnostic accuracy for meniscal lesions of the knee}

Scholten RJ, Devillé WL, Opstelten Wet al. The accuracy of physical diagnostic tests for assessing meniscal lesions of the knee: a meta-analysis. J Fam Pract 2001 Nov;50:938-44.

\section{QUESTION: In patients with meniscal lesions of the knee, what is the diagnostic accuracy of physical diagnostic tests?}

Source of funding: no external funding.

For correspondence: Dr R I P M Scholten, Dutch Cochrane Centre, Amsterdam, the Netherlands. R.J.Scholten@ AMC.UvA.NL

\section{Data sources}

Studies were identified by searching Medline (1966-99) and EMBASE/Excerpta Medica (1988-99) with terms describing knee joint, knee, menisci tibial, and effusion. The bibliographies of relevant studies were scanned.

\section{Study selection}

2 reviewers independently selected studies that were published in English, French, German, or Dutch; reported the accuracy of $\geqslant 1$ physical diagnostic test for the assessment of meniscal lesions of the knee; and used arthrotomy, arthroscopy, or magnetic resonance imaging (MRI) as the diagnostic standard. Studies were excluded if they did not have a reference group, included only people with positive test results, pertained to cadavers only, or considered physical examination under anaesthesia only.

\section{Data extraction}

2 reviewers independently assessed the quality of study methods and extracted data on the spectrum of lesions, number of patients, patients' ages, duration of symptoms, prevalence, sensitivity, specificity, and likelihood ratios.

\section{Main results}

13 studies (2231 patients) were included. The index test and diagnostic standard were assessed blindly in 2 studies. 9 studies used arthroscopy and 1 study used MRI as the diagnostic standard. Verification bias (ie, patients with an abnormal physical test finding had a greater likelihood of receiving the diagnostic standard) was present in most studies. The table shows the ranges for sensitivity, specificity, and likelihood ratios for the joint effusion test (4 studies), the McMurray test (11 studies), the joint line tenderness test (13 studies), and the Apley compression test (4 studies).

\section{Conclusion}

In patients with meniscal lesions of the knee, physical diagnostic tests have low diagnostic accuracy.
Test characteristics for diagnosing meniscal lesions of the knee*

\begin{tabular}{lcclllll} 
Tests & $\begin{array}{l}\text { Number of } \\
\text { studies }\end{array}$ & $\begin{array}{l}\text { Sensitivity } \\
\text { range }\end{array}$ & $\begin{array}{l}\text { Specificity } \\
\text { range }\end{array}$ & +LR range & -LR range \\
Joint effusion & 4 & $20 \%$ to $53 \%$ & $54 \%$ to $100 \%$ & 0.8 to $\infty$ & 0.7 to 1.1 \\
\hline McMurray test & 11 & $10 \%$ to $66 \%$ & $57 \%$ to & $98 \%$ & 1.5 to 9.5 & 0.4 to 0.9 \\
\hline $\begin{array}{l}\text { Joint line } \\
\text { tenderness }\end{array}$ & 13 & $28 \%$ to $95 \%$ & $5 \%$ to & $95 \%$ & 0.8 to 14.9 & 0.2 to 2.1 \\
\hline $\begin{array}{l}\text { Apley compression } \\
\text { test }\end{array}$ & 4 & $16 \%$ to $58 \%$ & $80 \%$ to & $99 \%$ & 0.8 to 19.5 & 0.5 to 1.1 \\
\hline *Diagnostic terms defined in glossary. & & & & & &
\end{tabular}

\section{COMMENTARY}

Can a primary care practitioner use the patient history and physical examination to correctly identify those with traumatic knee pain who would benefit from surgical intervention? In an excellent meta-analysis, Scholten et al provide evidence that joint tenderness or swelling does not predict the presence or absence of a torn meniscus, and a positive McMurray test result is minimally predictive of a meniscal tear. Other issues relating to the authors' research question require further attention.

First, most studies did not involve primary care providers. This omission biases the results toward a higher prevalence of meniscal tears and does not tell us whether primary practitioners do an examination similar to specialists. Second, the predictive value of such key questions in the patient's history as locking of the knee with flexion, the motion of injury, giving way of the knee, and knee swelling remains elusive. Third, methodological flaws may bias results. In 11 of 13 studies, the physical examination and the diagnostic standard (arthroscopy and MRI) were not assessed blindly, and patients with clinical suspicion of a meniscal lesion were more likely to have had surgery or an MRI. Finally, we do not know whether any test distinguishes a large traumatic tear (which will benefit from surgery) from a degenerative tear (which will respond to conservative management).

Should a primary provider continue to use joint effusion, tenderness, or a McMurray test in their physical examination? Until a large, well controlled prospective study involving primary care patients looks at the predictive power of both the patient history and the physical examination, we do not know for sure. In the meantime, it appears that physical examination is useful only when combined with the patient's history. For example, a 35 year old patient with an acute twisting injury, painful locking, and giving way has a greater chance of having a large, acute, surgically correctable meniscal tear than is a 56 year old patient who notes that a trivial squat produced pain and giving way. In the 35 year old patient, a positive McMurray test result increases the likelihood of surgical benefit, whereas in the 56 year old patient it adds no information.

Stanford Shoor, MD Kaiser Santa Clara Medical Center Santa Clara, California, USA

1 Stratford PW, Binkley J. A review of the McMurray test: definition, interpretation, and clinical usefulness.J Orthop Sports Phys Ther 1995;22:116-20. 